\title{
Antibacterial activity of watery and ethanolic extracts of Black Tea and peppermint
}

\section{(In vitro study)}

\author{
Abdullateef Mohammed Ahmed AL Beatushi Imad Hatem Hussein * Raghad S. Mouhamad ** \\ Khlood Abedalelah Al-Khafaji *** Mohammed Waheed Tayh **** Haider Abdulzahra Ghlaim***** \\ Razaq Waheed AL Zamily ****** Qusay khudair abbas ******* \\ Retired * Free Work ** ministry of science and technology \\ ***Ministry of Science and Technology ****ISC.CO. *****Biotechnology Research Center/Al-Nahrain University \\ $* * * * * *$ Free Work $\quad * * * * * * *$ Ministry of Oil \\ E-mail: haider.bsa@gmail.com
}

\begin{abstract}
:
Background:The most important medical challenge is the emergence of bacterial resistant to traditional antibiotics. So the need for new pharmaceutical compound derived from daily intake plant material. Mint and black tea used extensively in Arabic area as hot or cold drink Objective: investigate the bacterial activity of mint and black tea aqueous extract against many bacterial genera.

Material and methods: from the local market of Baghdad Province, Iraq, dry black tea was obtained; while, peppermint (Mentha piperita $\mathrm{L}$ ) was harvested from Iraqi plants during April 2020. Active ingredients extracted using either ethanol or water and their antibacterial activity evaluated against Staphylococcus aureus, S.epidermidis, Citrobacter sp and Klebsiella sp using well diffusion agar under invitro laboratory condition.

Results: Dried powder of each extract appeared with different color range from brown to black. Results recognized that $S$. aureus was susceptible to watery and ethanolic extract of both black tea and peppermint extracts. While, $S$. epidermidis showed resist to both plant extract and solvents used in extraction except minor inhibition with ethanolic extract of tea at $0.3 \%$ dose dose. Citrobacter spp gave susceptibility to watery extract of black tea as well as, watery and ethanolic of mint extract. Otherwise, Klebsiella spp. Growth inhibited by watery extract of black tea while, no bioactivity existed upon mint extract treatment.

Conclusion: Dose dependent manner existed for watery and ethanolic extracts for both plant material in their antibacterial activity.
\end{abstract}

Key words: Camellia sinensis, Mentha piperita, aqueous extraction, Staphylococcus aureus, Citrobacter sp.

\section{Introduction}

Medicinal plants as a term include various type of plants used in herbal medicine which have beneficial effect on health and can be administered for a specific condition either in modern medicine or traditional ancient medicine. Many reasons encourage to widely using medicinal plants in health practice such reasons: population rise, inadequate supply of drugs and their high cost, side effects of many synthetic drugs and appeared of multi drug resistance infectious bacteria that resist number of drugs under treatment. Most traditional herbs contains secondary metabolites which exert antibacterial activity against Gram positive and Gram negative pathogenic bacterial species $(1,2)$. Black tea and peppermint were used for centuries as a traditional drinking tea in the worldwide. Currently, biologically active compounds from peppermint and black tea sources always have been a great interest for scientists working on infectious diseases $(3,4)$. Their extracts showed a good antibacterial activity against many harmful pathogenic as Escherichia coli, Salmonella pullorum, Comamonas terrigena, Streptococcus faecalis, Acinatobacter sp, Streptococcus thermophiles, Lactobacillus bulgaricus, Staphylococcus pyogenes, S. aureus, Streptococcus pyogenes, Serratia marcescens, Mycobacterium avium, Salmonella typhi, Salmonella paratyphi A/B, Proteus vulgaris, Enterobacter aerogenes, Yersinia enterocolitica and Shigella dysenteriae $(5,6,7)$. A number of studies demonstrated that different part of plant contains different chemical composition of bioactive secondary metabolite as well as plant species can be effect on their antibacterial activity $(8,9)$; studies showed that the 
antibacterial activity of peppermint leaves extract against Gram negative bacilli was higher than of its stem extract (10). It seems that peppermint can become a novel target for synthesis of plant-derived drugs against a large spectrum of multidrug resistance bacteria $(11,12)$. As peppermint and black tea exhibits positive health potential as antibacterial agent against many species of pathogenic bacteria, beside, body weight management, hypertension, anti- mutagenic effect, antioxidant (13).

The most attractive biocompound is the Catechine which has many health advantages and belong to polyphenols compound that give biological and pharmaceutical activity for different disease. For a long time tea extract has drawn attention for its antibacterial activity and considerable as an alternative approach to prevent or reduce infections associated with wounds and burns (15). This research came to assess the ability of peppermint and black tea aqueous extract to inhibit bacterial growth of S.aureus, S. epidermidis, Citrobacter sp. and Klebsiella sp.

\section{Material and methods Plants preparation:}

From the local market of Baghdad Province, Iraq, dry black tea was obtained; while, peppermint (Mentha piperita L) was harvested from Iraqi plants during April 2020. Plant was cleaned from other herbs and rinsed with plenty of water then gently dried on paper towels. Meanwhile, plant was collected anddried using paper bags holding at dark place equipped to $25^{\circ} \mathrm{C}$ for nearly to 30 days.

Both black tea and dried leaves of peppermint were grounded into fine powder to pass $0.4 \mathrm{~mm}$ mesh panel. The samples were held in tight containers at $25^{\circ} \mathrm{C}$. Preparation of tea and mint aqueous extracts using either water or ethanol and was carried out according to the mentioned process (16). Dried samples (500 g) of mint and black tea were extracted with $100 \mathrm{ml}$ of ethanol or water and were kept at water path equilibrated to $60^{\circ} \mathrm{C}$ for 20 minutes. Meanwhile, vacuum filtration assembly was used to recover the extract and rotary evaporate was applied to dry the extract material. The final powder was weighted and stored in sealed bag at $4^{\circ} \mathrm{C}$ until used.

\section{Antibacterial activity:}

Bacteriological activities against Gram positive and Gram negative bacterial species were carried out against S. aureus, S. epidermidis, Klebsiella sp. and Citrobacter sp. The bacterial species under study were isolated from raw beef meat and cheese collected from local markets/ Baghdad following (17, 18, 19). Agar welldiffusion method on Mueller -Hinton agar was once applied for detecting the antibacterial activity (20).Bacterial species were activated at blood agar for $18 \mathrm{~h}$ at $37^{\circ} \mathrm{C}$. Swab of each bacterial growth was crashed out from blood agar plate and were suspended in sterilized peptone water. Turbidity was evaluated and compared with McFarland standard tube number 1 which equivalents approximately to $1 \times 10^{8} \mathrm{CFU} / \mathrm{ml}$. Cotton swab was immersed in bacterial suspension and was spread over Muller Hinton agar which let for 10 minute to ensure bacterial adherence. Meanwhile, borer applicator was sterilized by flame, cooled and pressed on the top of seeded Muller Hinton agar to make well with $7 \mathrm{~mm}$ radius, distance about $15 \mathrm{~mm}$ were kept between wells to qualify the aspect of plate. Each well was filled with $0.1,0.2$, and $0.3 \mu \mathrm{g} / \mathrm{ml}$ of extract; plates were stand for 10 minutes and were incubated for $24 \mathrm{~h}$ at $37{ }^{\circ} \mathrm{C}$. Control well was filled with either distilled water or ethanol $25 \%$ for aqueous and ethanolic preparation respectively. Three replica of each plate was prepared and the diameter of inhibition zone was recorded from the edge of the well. Data were analyzed by SPSS 22 standard statistical methods (21). 


\section{Results and Discussion}

Plants for centuries had formed sophisticated traditional medicinal importance and their natural products lead for alternative drug development (22).Peppermint and black tea are considered as the most popular and traditional drinking in Arabic area. Peppermint is cultured in Iraq as herbal plant by simple ways while black tea is imported from other producer countries as India and Syrilanka. We adopted here a simple and low cost and non-toxic extraction methods based on aqueous ethanolic solvent application. Antibacterial activity of both black tea and mint extract were evaluated against Gram positive and Gram negative bacteria under invitro laboratory condition. We recognized that $S$. aureus was susceptible to watery and ethanolic extract of both black tea and peppermint extracts. While, S. epidermidis showed resist to both plant extract and solvents used in extraction. Citrobacter sp gave susceptibility to watery extract of black tea as well as, watery and ethanolic mint extract. Otherwise, Klebsiella sp. Growth inhibited by watery extract of black tea while, no bioactivity existed upon mint extract treatment Figure(1).Our findings illustrated in Table (1) demonstrated that plant type, chemical properties of solvent used in extraction procedure as well as method of extraction and condensation of extracts played an important role in their antibacterial activity against Gram positive and Gram negative bacteria such finding was in agreement with (23) and (24) in their suggestion about the chemical properties of the solvent and method of extraction which show distinct behavior.

Reports dealing with the chemical composition of mint species suggested that many factors would interfere with the extraction of bioactive ingredients. Some of them were the environmental parameters such as growth location, soil characteristics, moisture and temperature. Other parameters might play a role in the chemical composition and the concentration of active compounds such as phase of the plant collection and the part of plant that used for extraction; type of material as fresh plant or dried powder could be responsible for bioactivity $(25,26)$. 


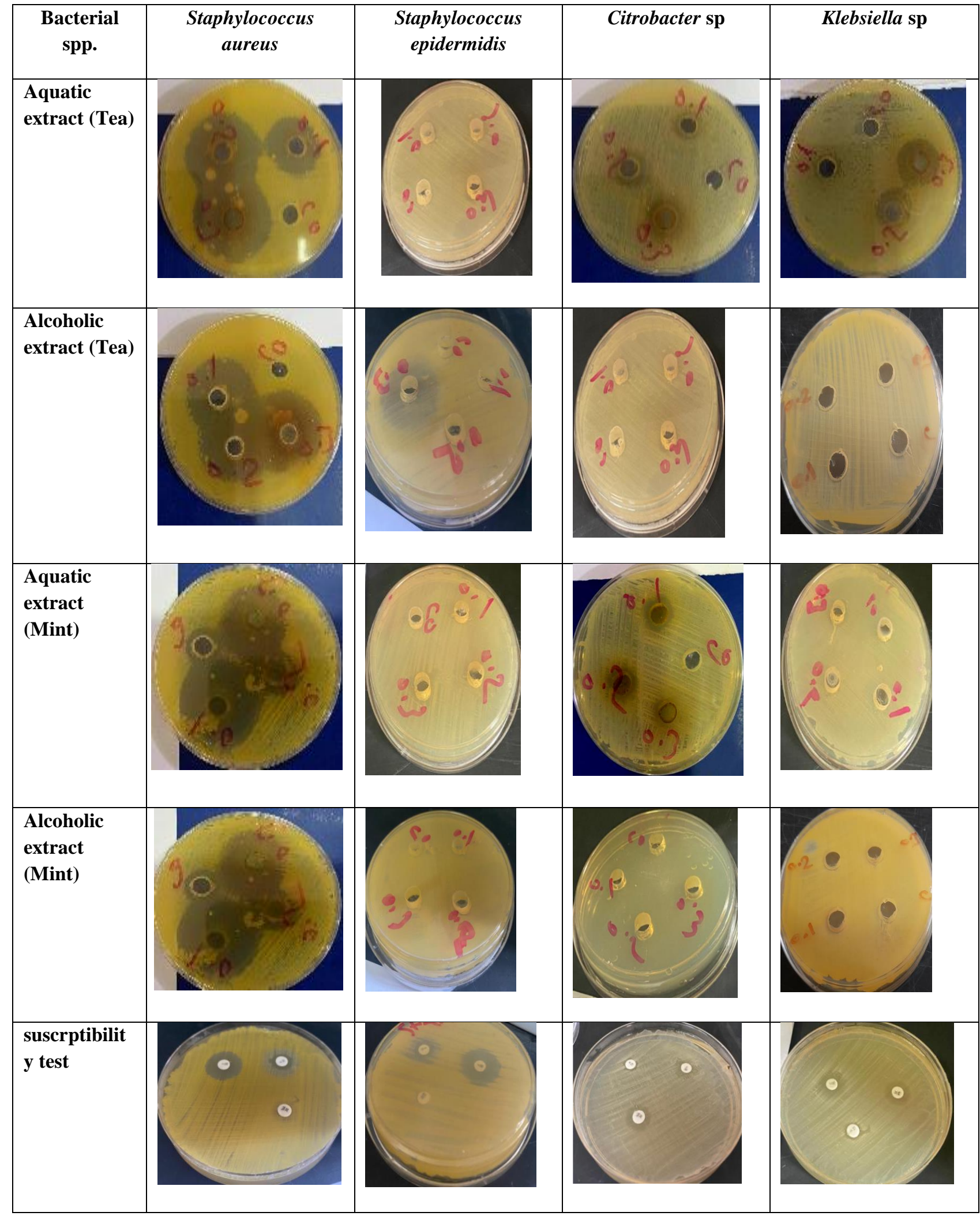

Figure (1): The bacterial susceptibility test using well diffusion agar. 1= watery extract of black tea;2= ethanolic extract of black tea;3= watery extract of peppermint; $4=$ ethanolic extract of peppermint, $0.1,0.2,0.3$ were concentration, co=control 
Table (1): Descriptive statistics of the minimum inhibitory of the Tea and mint extract against bacterial species

\begin{tabular}{|c|c|c|c|c|c|c|c|c|}
\hline \multirow{2}{*}{$\begin{array}{l}\text { Type of bacteria } \\
\text { Type of extract }\end{array}$} & \multicolumn{2}{|c|}{ Staphylococcus aureus } & \multicolumn{2}{|c|}{$\begin{array}{l}\text { Staphylococcus } \\
\text { epidermides }\end{array}$} & \multicolumn{2}{|c|}{ Citrobacter spp } & \multicolumn{2}{|c|}{ Kliebsella spp } \\
\hline & Water & Ethanol & Water & Ethanol & Water & Ethanol & Water & Ethanol \\
\hline Tea Ex. ( 0.1\%) & 22 & 35 & $\mathbf{0}$ & $\mathbf{0}$ & $\mathbf{0}$ & $\mathbf{0}$ & $\mathbf{0}$ & $\mathbf{0}$ \\
\hline Mint Ex. ( 0.1\%) & 38 & 40 & $\mathbf{0}$ & $\mathbf{0}$ & 5 & 25 & $\mathbf{0}$ & $\mathbf{0}$ \\
\hline Tea Ex. ( $0.2 \%)$ & 35 & 35 & $\mathbf{0}$ & $\mathbf{0}$ & 7 & $\mathbf{0}$ & 8 & $\mathbf{0}$ \\
\hline Mint Ex. ( 0.2\%) & 33 & 38 & $\mathbf{0}$ & $\mathbf{0}$ & 7 & $\mathbf{0}$ & $\mathbf{0}$ & $\mathbf{0}$ \\
\hline Tea Ex. $(0.3 \%)$ & 35 & 32 & $\mathbf{0}$ & 8 & 12 & $\mathbf{0}$ & 16 & $\mathbf{0}$ \\
\hline Mint Ex. ( 0.3\%) & 25 & 33 & $\mathbf{0}$ & $\mathbf{0}$ & 10 & 15 & $\mathbf{0}$ & $\mathbf{0}$ \\
\hline Mean & 31.3 & 35.5 & $\mathbf{0}$ & 1.3 & 6.8 & 6.7 & 4.0 & $\mathbf{0}$ \\
\hline Standard Error & 2.6 & 1.2 & $\mathbf{0}$ & 1.3 & 1.7 & 4.4 & 2.7 & $\mathbf{0}$ \\
\hline Standard Deviation & 6.3 & 3.0 & $\mathbf{0}$ & 3.3 & 4.2 & 10.8 & 6.7 & $\mathbf{0}$ \\
\hline Kurtosis & -1.3 & -0.9 & - & 6.0 & 0.7 & 0.2 & 1.4 & - \\
\hline Skewness & -0.8 & 0.5 & - & 2.4 & -0.6 & 1.3 & 1.5 & - \\
\hline $\begin{array}{l}\text { Confidence Level } \\
(\mathbf{9 5 . 0 \% )}\end{array}$ & 6.7 & 3.2 & $\mathbf{0}$ & 3.4 & 4.4 & 11.3 & 7.0 & 0 \\
\hline
\end{tabular}

Tea extract had positive impact for the four bacterial species under study; S. aureus was more susceptible than other specie for the tow extraction procedures. Watery extract was more reliable than ethanol solvent used in extraction. Dose dependent appeared for watery extract against each of S. aureus, Citrobacter spp and Klebsiella spp vis versa ethanolic extract against S. aureus. Bioactivity of Black tea against bacteria might contribute to its chelating capability for metal ions that lead to ferric reduction $(27,28)$. This activity led to bacterial cell starvation and reduction of growth rate. Also, the presence of polyphenols and tannin which extensively extracted in aqueous extracts of peppermint and black tea might give its potential as antibacterial agent. Tannin might affect bacterial growth through the inhibition of extracellular important enzymes, prevention bacteria from acquiring important substances required for their reproduction and growth, as well as, their negative impact on the microbial metabolism via inhibition of oxidative phosphorylation $(14,29,30,31,32)$.

Recent results indicated that $S$. aureus was high susceptible to both watery and ethanolic mint extract; Citrobacter spp demonstrated high susceptibility to ethanolic mint extract in compared with watery extract. While other bacterial species S. epidermidis and Klebsiella spp resisted both mint extract as presented in percentage of resistance against extracts under study Figure (2).

The inhibitory picture against $S$. aureus showed that low extract concentration gave the best inhibition zone in compared with high concentration for both extract procedures and this might due to the diffusion effect of viscous extracts. While, dose dependent recognized in watery mint extract against Citrobacter spp in compared with alcoholic extract for the same bacterial species. Our results were in accordance with (24) since various watery and ethanolic extracts of leave exhibited antibacterial activity against many pathogenic 
bacterial species. Also, our noted results for Gram positive susceptibility in contrast with the resistance of Gram negative bacterium have been reported elsewhere and might explained through the knowledge of the presence of hydrophobic lipopolysaccharides in the outer membrane of Gram negative bacteria, which provides protection against different antibacterial agents. This structure prevents the depolarization, pores formation and increasing of membrane permeability $(33,34)$. Result presented in Figure (2) indicated that aqueous watery extract of mint showed lower antibacterial activity against Citrobacter spp and this might due to low efficiency of water to extract the active ingredients present in mint (35). On the other hand, Gram negative bacteria surrounded by complex tow membrane layer which acts as a natural barrier in bacterial cell wall and prevents the exotic material to pass through the hydrophobic lipopolysaccharide in outer membrane. This was well documented by other researches who also found that stronger antibacterial activity of mint extract against Gram positive bacteria than against Gram negative bacteria (26).

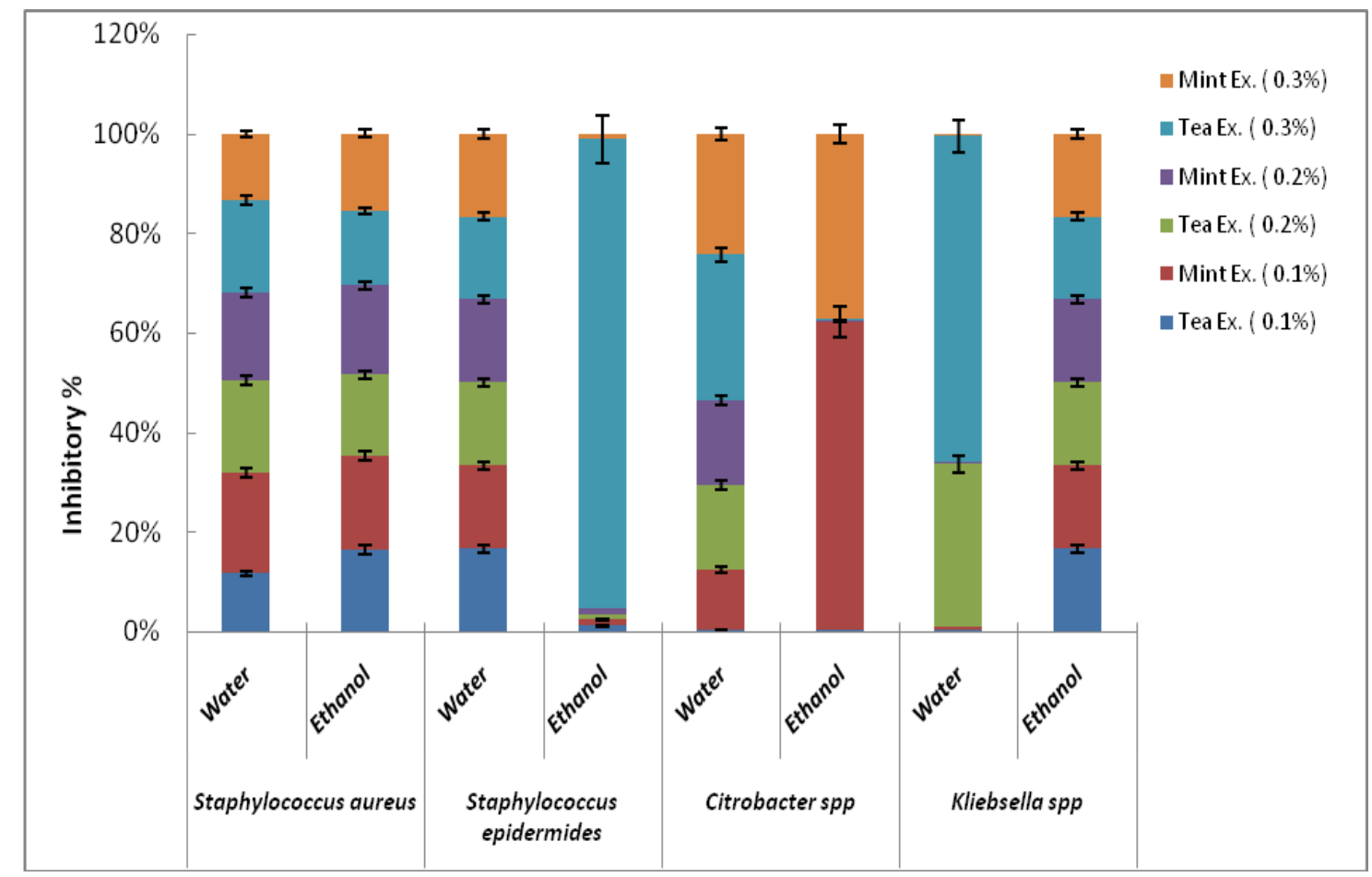

Figure (2): The minimum inhibitory for Tea and mint extract against bacterial species

It is well known that mint is a rich source of essential oils beside its high content of phenolic based substances. The synergistic actions among bioactive compound existed in the tested extract might exert the antibacterial activity such assumption was in accordance with other researches $(26,31)$.

Many critical parameters affecting the antibacterial activity include: the chemical composition of plant extract, the concentration of active ingredients, as well as the type of tested microorganism. The composition of active substances may be determined by plant cultivation method, environmental conditions, time of plant harvesting, method of plant drying, and storage conditions, as well as extraction method $(36,37)$.

\section{Conclusion}

Urgent of increased bacterial resistant to wide range of antibiotics lead scientists to return to the traditional ancient medicinal plant. Black tea and peppermint is both familiar for Iraqi population as daily drinks. The active ingredients of mint and black tea under study were responsible for their antibacterial activity against the most abundant and harmless S. aureuswhile, result presented here was assured that mint extract had the inhibitory activity against Citrobacter sp. We recommended here to use herbal extract under study as a food preservative to inhibit $S$. aureus and Citrobacter sp. that could be a source for food poisoning. Also, to treat infection in opened wound and burns as well as many others related disease. 


\section{References}

1. Namita P, Mukesh R. Medicinal plants used as antibacterial agents: A review. Inter. Res. J. (2012); 3(1): 32-40.

2. Cheesman MJ, Ilanko A, Blonk B, Cock IE. Developing New Antibacterial Therapies: Are Synergistic Combinations of Plant Extracts/ Compounds with Conventional Antibiotics the Solution?. Pharmacogn Rev. (2017); 11(22): 57- 72.

3. McKay D, Blumberg JB. A review of the bioactivity and potential health benefits of peppermint tea (Mentha piperitaL). Phytotherapy Res. (2006); 20(8): 619-633.

4. Khan N, Mukhtar H. Tea polyphenols for health promotion. Life Sci. (2007); 81(7): 519-533.

5. Mughal T, Tahir A, Qureshi S, Nazir T, Rasheed M. Antibacterial activity of black tea against Strptococcus mutans and its synergism with antibiotics. J App Pharm .(2010); 2(2): 60- 67.

6. Saleh BH, Ibrahim RN, Abdul-Wahed HE, Salih ZT. Study the antibacterial activity of green tea leaves Camellia sinensis ethanolic extract against different pathogenic bacteria isolated from urinary tract infections. Plant Archives. (2020); 20(1): 1077-1084.

7. Qing L, Xiao M, Ya L, Cai-Ning Z, Guo-Yi T, Hua-Bin L. Antibacterial and Antifungal Activities of Spices review.Int J Mol Sci. (2017); 18(6): 1283.

8. Pagare S, Bhatia M, Tripathi N, Pagare S, Bansal YK. Secondary metabolites of plants and their role: Overview. Current Trends in Biotechnology and Pharmacy. (2015); 9(3): 293-304.

9. Zhao Y, Wu Y, Wang M. Bioactive Substances of Plant Origin. In: Cheung P. Mehta B. (eds) Handbook of Food Chemistry. (2015) Springer, Berlin, Heidelberg.

10. Bupeshi G, Amutha C, Handagopal S, Ganeshkumar A, Sureshkumar P, Mural KS. Antibacterial activity of Mentha piperita L. (peppermint) from leaf extracts - a medicinal plant. Acta Agriculturae Slovenica.(2007); 89(1): 73-79.

11. Singh R, Shushni MAM, Belkheir A. Antibacterial and antioxidant activities of Menthapiperita L. Arabian Journal of Chemistry. (2015); 8: 322-328.

12. Muntean D, Licker M, Alexa E, Popescu I, Jianu C, Buda V, Dehelean CA, Ghiulai R, Horhat F, Horhat D, Danciu C. Evaluation of essential oil obtained from Mentha piperita L. against multidrugresistant strains. Infection and Drug Resistance. (2019);12: 2905-2914.

13. Kodagoda KHGK, Wickramasinghe I. Health benefits of green and black Tea: A Review. International Journal of Advanced Engineering Research and Science (IJAERS). (2017); 4 (7):107- 112.

14. Chan EW, Soh EY, Tie PP, Law YP. Antioxidant and antibacterial properties of green, black, and herbal teas of Camelliasinensis. Pharmacognosy Res. (2011); 3(4): 266-272.

15. Fatemi MJ, Nikoomaram B, Rahimi AA, Talayi D, Taghavi S, Ghavami Y. Effect of green tea on the second degree burn wounds in rats. Indian J Plast Surg. (2014); 47(3): 370- 374.

16. FAO/WHO Expert Committee on Food Additives 86th Meeting 2018.

17. Alkhafaji KA, Khames IS, Jaffer MM, Mahmood SA, Abidalah MA.Contribution of Protease, Lipase, Hemolysin and Biofilm in Persist of Staphylococcus aureus Isolated fromFood Sources. Acta Scientific Agriculture. (2019); 3(10): 70-76.

18. Messaoudi A, Gtari M, Boudabous A, Wagenlehner F. Identification and susceptibility of Klebsiella and Enterobacter spp. Isolated from meat products. African J. Microbiol. Res. (2009); 3(7): 362-369.

19. Milhem H, Azizieh A, Abou younes A. Prevalence of Escherichia coli and Citrobacter freundii in raw beef from major Abattoirs location Damascus and countryside, Syria. Inter. J. Chem. Tech. Res. (2016); 9(2):290-296.

20. Shaheen AY, Sheikh AA, Rabbani M, Aslam A, Bibi T, Liaqat F, Muhammad J, Rehmani SF. Antibacterial activity of herbal extracts against multi-drug resistant Escherichia coli recovered from retail chicken meat. Pak. J. Pharm. Sci. (2015); 28 (4) :1295-1300.

21. Risala H Allami, Raghad S Mouhamad, Sura A Abdulateef, Khlood abedalelah al-Khafaji. Antibacterial Activity of Herbal Mixture Extract Combination on Microorganisms Isolated from Urinary Tract infection. Revista Bionatura. (2020); 5(4):11-17.

22. Newman DJ, Cragg GM, Snader KM. The influence of natural products upon drug discovery. Natural product Res. (2000); 17: 215-234.

23. Pinelo M, Manzocco L, Nuñez MJ, Nicoli MC. Solvent effect on quercetin antioxidant capacity. Food Chem. (2004); 88(2): 201-207.

24. Abkhoo J, Jahani S. Antibacterial effects of aqueous and ethanolic extracts of medicinal plants against pathogenic strains. Int. J. Infect. (2017); 4 (2): e42624.

25. Salehi B, Stojanovi'c-Radi'c Z, Mateji'c J, Sharopov F, Antolak H, Kr cegiel D, Sen S, Sharifi-Rad M, Acharya K, Sharifi-Rad R. Plants of genus Mentha: From farm to food factory. Plants (2018); 7: 70.

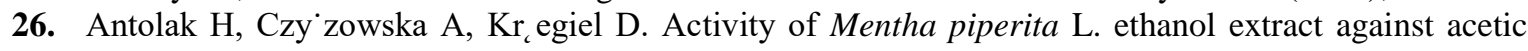
acid bacteria Asaia spp. Foods. (2018); 7: 171. 
27. Kaltwasser JP, Werner E, Schalk K, Hansen C, Gottschalk R, Seidl C. Clinical trial on the eVect of regular tea drinking on iron accumulation in genetic haemochromatosis. Gut. (1998); 43: 699-704.

28. Ben Lagha A, Haas B, Grenier D. Tea polyphenols inhibit the growth and virulence properties of Fusobacterium nucleatum. Sci Rep. (2017); 7: 44815.

29. Min BR, Pinchak WE, Merkel R, Walker S, Tomita G, Anderson RC. Comparative antibacterial activity of tannin extracts from perennial plants on mastitis pathogens. Sci Res Essay. (2008); 3: 6673.

30. Doss A, Mohammed MH, Dhanabalan R. Antibacterial activity of tannins from the leaves of Solanum trilobatum Linn. Indian J Sci Technol. (2009); 2: 41-43.

31. Scalbert A. Antibacterial properties of tannins. Phytochemistry. (1991); 30: 3875- 3883.

32. Bupesh G, Amutha C, Nandagopal S, Ganeshkumar A, Sureshkumar P, Murali KS. Antibacterial activity of Mentha piperita L. (peppermint) from leaf extracts-A medicinal plant. Acta Agric. Slov. (2007); 89: 73-79.

33. Raetz CRH, Whitfield C. Lipopolysaccharide endotoxins. Annu. Rev. Biochem. (2002); 71: 635- 700.

34. Ebbensgaard A, Mordhorst H, Aarestrup FM, Hansen EB. The Role of Outer Membrane Proteins and Lipopolysaccharides for the Sensitivity of Escherichia coli to Antibacterial Peptides. Front. Microbiol. (2018); 9: 2153.

35. El-Mahmood AM, Doughari JH, Ladan N. Antibacterial screening of stem bark extracts of Vitellaria paradoxa against some enteric pathogenic microorganisms. African J Pharm Pharmacol. (2008); 2(5): 89- 94.

36. Perumalla AVS, Hettiarachchy NS. Green tea and grape seed extracts-Potential applications in food safety and quality. Food Res. Int. (2011); 44: 827-839.

37. Liu W, Yin D, Li N. Influence of Environmental Factors on the Active Substance Production and Antioxidant Activity in Potentilla fruticosa L. and Its Quality Assessment. Sci Rep. (2016); 6: 28591. 